OLIVEIRA, A. T.; JUNQUEIRA, A. M. R; FRANÇA, F. H. Impacto da Irrigação por aspersão convencional na dinâmica populacional da traça-dascrucíferas em plantas de repolho, Horticultura Brasileira, Brasília, v. 18, n. 1, p. 37-40, março 2000.

\title{
Impacto da irrigação por aspersão convencional na dinâmica populacional da traça-das-crucíferas em plantas de repolho ${ }^{1}$.
}

\author{
Aurélio Tinoco de Oliveira; Ana Maria R. Junqueira ${ }^{2}$; Félix Humberto França ${ }^{3}$ \\ ${ }^{2}$ UnB - Faculdade de Agronomia e Medicina Veterinária, Núcleo de Apoio à Competitividade e Sustentabilidade da Agricultura, C. \\ Postal 4.508, 70.910-970, Brasília - DF; ${ }^{3}$ Embrapa Hortaliças, C. Postal 218, 70.359-970, Brasília - DF.
}

\section{RESUMO}

Para avaliar o impacto da irrigação via aspersão convencional na dinâmica populacional da traça-das-crucíferas foram realizados dois experimentos. O primeiro composto por dois ensaios, foi realizado na Embrapa Hortaliças. No primeiro ensaio, larvas de terceiro e quarto estágio foram colocadas em 16 plantas de repolho, cv. Kenzan, com folhas abertas, 40 dias após a semeadura e em 16 plantas iniciando a formação da cabeça. Após um período de 24 horas, os vasos com as plantas foram conduzidos ao campo, onde metade deles recebeu irrigação por aspersão convencional. A lâmina aplicada foi de $23 \mathrm{~mm}$ em trinta minutos. A outra metade das plantas serviu como testemunha. No segundo ensaio, realizado com a mesma metodologia, larvas de primeiro e segundo estágios foram colocadas em quarenta plantas. No segundo experimento realizado na Fazenda Água Limpa, Universidade de Brasília, o delineamento experimental utilizado foi inteiramente casualizado, com três tratamentos (inseticida clorfluazuron com aplicações semanais de $400 \mathrm{ml} / \mathrm{ha}$; clorfluazuron aplicado quando atingido o nível de dano de seis furos, em média, nas quatro folhas centrais e testemunha sem inseticida, em dez repetições, totalizando trinta parcelas com 24 plantas cada uma. Foram aplicados $400 \mathrm{~mm}$ de água à cultura durante o ciclo. As pulverizações semanais do inseticida e o acompanhamento do nível de dano em cinco plantas ao acaso, em cada parcela, tiveram início no $36^{0}$ dia após o transplante. As notas foram atribuídas (104 dias após o transplante) às oito plantas centrais das parcelas, conforme a escala: $01=$ folhas raspadas ou sem danos, 02 = folhas com furos pequenos (pouco dano); $03=$ folhas com furos grandes (muito dano); $04=$ plantas totalmente danificadas . Verificou-se que a precipitação tem influência no controle da traçadas-crucíferas, promovendo $52 \%$ de remoção de larvas quando as plantas estavam com as folhas abertas e quando larvas de primeiro e segundo estágios foram utilizadas. Não foi observada diferença estatística entre os tratamentos "inseticida semanal" e "inseticida aplicado quando atingido o nível de dano". Também não houve diferença estatística entre os tratamentos "inseticida aplicado quando atingido o nível de dano" e a testemunha.

Palavras-chave: Plutella xylostella, irrigação, manejo integrado de pragas.

\section{ABSTRACT}

Impact of sprinkler irrigation on diamondback moth injuries on cabbage plants.

Two experiments were carried out to evaluate the impact of sprinkler irrigation on Diamondback moth injuries on cabbage plants (cv. Kenzan). The first experiment, composed by two trials, was carried out at Embrapa Hortaliças. In the first trial, larvae of third and forth stages were transferred to 16 plants with open leaves, 40 days after sowing and on 16 'Kenzan' plants beginning to form head. After 24 hours, pots with cabbage plants were transferred to the field, where half of them were irrigated using sprinkler irrigation system for 30 minutes per day, receiving depth of water of $23 \mathrm{~mm}$. The other half of the pots were the control treatment. On the second trial, carried out at the same way, larvae of the first and second stage were transferred to 40 cabbage plants. The second experiment was carried out at Fazenda Água Limpa, University of Brasília. The experimental design was completely randomized with three treatments (clorfluazuron weekly applied - $400 \mathrm{ml} / \mathrm{ha}$; clorfluazuron applied at crop economic threshold and control, without clorfluazuron) in 10 replicates, total of 30 plots with 24 plants each. It was applied 400 $\mathrm{mm}$ of water during crop cycle. The weekly clorfluazuron applications and the weekly crop economic threshold evaluation began 36 days after transplanting. Grades were attributed to eight plants per plot during harvest according to the degree of injuries observed: $01=$ no damage; $02=$ few damages; $03=$ leaves with many injuries; $04=$ plant totally damaged. Sprinkler irrigation has influence on Diamondback moth control by removing $52 \%$ of the larvae when first and second stage larvae were used. No statistically significant difference was observed between the grades of the plants that received clorfluazuron weekly and the plants that received it at crop economic threshold and between the latter treatment and the control.

Keywords: Plutella xylostella, irrigation, integrated pest management.

\section{(Aceito para publicação em 07 de fevereiro de 2000)}

\begin{abstract}
A produção mundial de repolho (Brassica oleracea var. capitata) situa-se em torno de 42,2 milhões de toneladas, sendo que no Distrito Federal e região do entorno a produção anual é de 6.931,5 t/ano (EMATER, 1996). Dentre
\end{abstract}

as pragas que atacam a cultura, a traçadas-crucíferas (Plutella xylostella) é um fator limitante na produção. As larvas da traça ao perfurarem as cabeças de repolho diminuem o valor comercial do produto. As medidas de controle da traça baseiam-se no uso de inseticidas de amplo espectro usados em doses elevadas e em intervalos muito curtos. Estima-se o custo anual para o manejo da traça em um bilhão de dólares (Shelton et al., 1994). Segundo Villas Bôas et al. (1990)

\footnotetext{
${ }^{1}$ Trabalho realizado como parte das exigências para obtenção do grau de Engenheiro Agrônomo pelo primeiro autor.
} 
aplicações contínuas de produtos utilizados para o controle de Plutella xylostella levam ao rápido aparecimento de indivíduos resistentes. No Distrito Federal, piretróides não atingiram controle satisfatório da traça (França et al., 1984). A traça-das-crucíferas é considerada a praga de maior importância econômica para o repolho na região do Distrito $\mathrm{Fe}$ deral (Castelo Branco \& Melo, 1992) e o período de desenvolvimento de altas populações ocorre entre os meses de junho a outubro (França et al., 1984).

Estratégias de manejo devem ser realizadas para diminuir a pressão de seleção imposta pelos inseticidas à traça conferindo-lhe resistência. Guimarães \& Villas Bôas (1989) ao estudarem a flutuação populacional da traça em repolho, objetivando definir a melhor época de plantio na região do Distrito $\mathrm{Fe}$ deral, determinaram que no plantio da época seca (julho) obteve-se o pico populacional aos 70 dias após o transplante com 5,7 larvas/planta e que no plantio das águas (dezembro) o pico ocorreu apenas no final do ciclo, atingindo 2,0 larvas/planta. Castelo Branco et al. (1996) recomendam, para controle da traça-das-crucíferas em repolho, que as aplicações de inseticidas sejam iniciadas a partir da formação das cabeças e somente quando forem encontrados, em média, 6 furos nas quatro folhas centrais.

A precipitação tem grande influência no desenvolvimento populacional da traça-das-crucíferas na cultura do repolho ao remover larvas nos primeiros estágios de vida (Carballo et al., 1989). Experimentos visando o controle da traça-das-crucíferas resultaram em 75\% (Castelo Branco \& Melo, 1992), 95\% (Guimarães \& Villas Bôas, 1989) e 50\% (Carballo et al., 1989) de cabeças comerciais, quando do cultivo em época de chuva e sem aplicação de inseticidas. Segundo Castelo Branco et al. (1997) a irrigação efetuada durante a noite reduz o acasalamento da traça e pode contribuir para diminuir a população da praga na área e, irrigações efetuadas durante o dia podem contribuir para a redução da população da traça por meio da remoção de ovos das plantas. Costa et al. (1996) observaram significativa remoção de ovos de T. absoluta (traça-do-tomateiro) em cultivo de tomate sob pivô-central. McHugh \& Foster (1995), em estudo sobre o potencial do uso da irrigação por aspersão como ferramenta de gerenciamento para controle da traça no repolho, demonstraram que o uso mais efetivo da irrigação ocorreu quando a aplicação da água aconteceu diariamente, intermitentemente nas horas noturnas, com um índice de 85,9\% de redução na infestação da traça. Junqueira et al. (1998) ao avaliarem o impacto de diferentes lâminas e sistemas de irrigação nos danos de Plutella xylostella em plantas de repolho, observaram número de danos bem inferior nas plantas sob irrigação por aspersão, em comparação à irrigação por gotejamento.

O objetivo deste trabalho foi avaliar o impacto da água aplicada à cultura do repolho, via sistema de irrigação por aspersão convencional, na remoção de larvas e fazer um estudo comparativo do controle da traça-das-crucíferas utilizando água; água e inseticida (Clorfluazuron com aplicações semanais); e água e inseticida Clorfluazuron (aplicado quando era atingido um nível de dano pré-estabelecido para a cultura do repolho).

\section{MATERIAL E MÉTODOS}

O primeiro experimento foi composto por dois ensaios, onde foram utilizados diferentes estágios da larva de Plutella xylostella com a finalidade de quantificar a remoção de larvas da traça por meio da utilização da irrigação por aspersão convencional. O primeiro experimento foi realizado de agosto a outubro de 1996 na Embrapa Hortaliças, Brasília - DF.

Primeiramente realizou-se um ensaio com larvas de terceiro e quarto estágios e após o término deste realizouse o ensaio com larvas de primeiro e segundo estágio. Para ambos os ensaios, a metodologia utilizada foi a mesma. Plantas de repolho, cv. Kenzan, foram produzidas em vasos em casa-de-vegetação. As mudas foram plantadas a intervalos de 30 dias de forma que durante a realização dos ensaios, metade das mudas tinha entre 40-50 dias de idade (folhas abertas) e a outra metade tinha 70 dias (iniciando a formação da cabeça). Larvas de quarto estágio e pupas da traça foram coletadas em plantas de repolho no campo experimental da Embrapa Hortaliças e cultivadas em laboratório em temperatura controlada de $20^{\circ} \mathrm{C}$ e fotoperíodo de 16 horas luz. Após a eclosão das pupas os adultos foram colocados em gaiolas juntamente com duas a três folhas de repolho para a oviposição. As folhas com ovos foram transferidas para caixas plásticas e armazenadas em câmara com temperatura e luz controlada. Ao atingirem os estágios desejados as larvas foram levadas para a casa-de-vegetação e transferidas para as plantas de repolho. Dez larvas foram depositadas nas quatro folhas centrais de cada planta de repolho, 32 plantas no primeiro ensaio e 40 plantas no segundo ensaio. Após 24 horas, as plantas foram conduzidas ao campo, onde metade do total das plantas de ambas as idades foram irrigadas pelo sistema de aspersão convencional, durante um período de 30 minutos, com uma lâmina de água de $23 \mathrm{~mm}$. A outra metade serviu de testemunha, não recebendo irrigação. Após a irrigação as plantas foram reconduzidas à casa-devegetação onde realizou-se a contagem das larvas remanescentes.

O segundo experimento, que teve como finalidade comparar o controle da traça-das-crucíferas utilizando água, água + $400 \mathrm{ml} / \mathrm{ha}$ de clorfluazuron (aplicações semanais) e água $+400 \mathrm{ml} / \mathrm{ha}$ de clorfluazuron (aplicado quando atingido o nível de dano da traça - 06 furos em média - nas quatros folhas centrais da planta), teve início em maio de 1997 na Fazenda Água Limpa da Universidade de Brasília. O delineamento utilizado foi inteiramente casualizado, com 3 tratamentos, 10 repetições, com quatro linhas de 06 plantas cada uma, totalizando 24 plantas por parcela. As sementes do híbrido Kenzan foram plantadas em bandejas, e mantidas protegidas sobre telado até chegarem ao estágio de 5 a 6 folhas definitivas (30 dias) quando foi realizado o transplante. O terreno foi preparado com passagem de arado, grade aradora e enxada rotativa. $\mathrm{O}$ espaçamento utilizado foi de $0,8 \times 0,3 \mathrm{~m}$. O plantio foi feito em sulco ao nível do solo em 11 de junho de 1997 , e as adubações foram realizadas no sulco conforme recomendado para a cultura, tendo por base a análise do solo. Os aspersores foram dispostos em forma de retângulo à uma distância de 12 metros entre aspersores e 18 metros entre linhas. Foram instalados "pluviômetros tipo lata" 
em cada parcela para acompanhamento e controle da quantidade e uniformidade da água aplicada via irrigação. Após a instalação do equipamento de irrigação, foi realizado um teste onde foi observada a aplicação de uma lâmina de $11,46 \mathrm{~mm} /$ hora com um Coeficiente de Uniformidade de Christiansen de $84 \%$. A partir do teste, determinou-se o tempo de irrigação da cultura de acordo com o seu estágio de desenvolvimento. Em cada irrigação realizada, anotava-se a quantidade de água retida em cada pluviômetro e calculavase a lâmina precipitada. Utilizou-se o turno de rega praticado pelos produtores da região: intervalo de dois dias no estágio inicial da planta e de três dias quando decorridos trinta dias do transplante. Foram aplicados $400 \mathrm{~mm}$ de água à cultura durante o ciclo.

No trigésimo sexto dia após o transplante (planta iniciando a formação da cabeça), iniciou-se as pulverizações com o inseticida clorfluazuron em dez parcelas em aplicações semanais. Para avaliação do nível de dano, para aplicação ou não de inseticida, a contagem do número de furos foi realizada semanalmente, no mesmo período em que tiveram início as pulverizações semanais, em cinco plantas obtidas ao acaso, dentre as 24 plantas que constituíam as dez parcelas pré-determinadas. $\mathrm{Na}$ avaliação, as notas foram atribuídas às oito plantas centrais de cada parcela, ficando o restante como bordadura. Na colheita, realizada aos 104 dias após o transplante, as cabeças de repolho foram avaliadas para os danos da traçadas-crucíferas de acordo com a seguinte escala de nota: $01=$ folhas raspadas ou sem dano; $02=$ folhas com furos pequenos (pouco dano); 03= folhas com furos grandes (com dano); 04= plantas com folhas totalmente danificadas (muito dano). As notas foram atribuídas por dois avaliadores. Foi registrado ainda o peso individual de cada cabeça.

Os resultados de ambos experimentos foram transformados em $\sqrt{\mathrm{x}+1}$ (Snedecor \& Cochran, 1989). Após a transformação, os dados foram submetidos à análise de variância e as médias foram comparadas pelo teste de Tukey a $5 \%$ de probabilidade.

\section{RESULTADOS E DISCUSSÃO}

No primeiro ensaio do primeiro experimento, onde foram utilizadas larvas

Tabela 1. Porcentagem de remoção de larvas* de terceiro e quarto estágio de Plutella xylostella em plantas de repolho, por meio de irrigação por aspersão. Brasília, Embrapa Hortaliças, 1996.

\begin{tabular}{|c|c|c|c|}
\hline Idade da Planta & Testemunha & Irrigadas $(23 \mathrm{~mm})$ & Média \\
\hline 40 dias & $35,00 * *$ & 33,75 & 34,68 a \\
\hline 70 dias & 16,25 & 33,75 & $25,00 \mathrm{a}$ \\
\hline Média & $25,62 A$ & $33,75 \mathrm{~A}$ & \\
\hline
\end{tabular}

* Porcentagem de remoção de larvas, incluídas perdas no transporte.

** Média de oito plantas. Coeficiente de variação $=21,04 \%$.

Médias seguidas pela mesma letra (maiúscula ou minúscula) não diferem estatisticamente entre si, pelo teste de Tukey, a $5 \%$ de probabilidade.

Tabela 2. Porcentagem de empupamento verificado em relação à quantidade de larvas remanescentes* por planta, após a irrigação de $23 \mathrm{~mm}$ de lâmina de água aplicada via sistema de irrigação por aspersão convencional. Brasília, Embrapa Hortaliças,1996.

\begin{tabular}{ccccc}
\hline Planta & $\begin{array}{c}\text { Test. } \\
\text { (40 dias) }\end{array}$ & $\begin{array}{c}\text { Irrig. } \\
\text { (40dias) }\end{array}$ & $\begin{array}{c}\text { Test. } \\
\text { (70 dias) }\end{array}$ & $\begin{array}{c}\text { Irrig. } \\
\text { (70 dias) }\end{array}$ \\
\hline 01 & 33,3 & 62,5 & 50,0 & 40,0 \\
02 & 33,3 & 83,3 & 33,3 & - \\
03 & - & 80,0 & 50,0 & 20,0 \\
04 & 42,8 & 60,0 & 30,0 & 33,3 \\
05 & 37,5 & 16,6 & 25,0 & 50,0 \\
06 & 20,0 & 85,7 & 20,0 & 42,8 \\
07 & 100 & 62,5 & 25,0 & 40,0 \\
08 & 66,6 & 37,5 & 33,3 & 11,1 \\
\hline Média & 41,6 & 61,0 & 33,3 & 29,6 \\
\hline
\end{tabular}

* Para cálculo da porcentagem de empupamento verificado, considerou-se como total remanescente de larvas a quantidade de larvas acrescida da quantidade de pupas não removidas pela irrigação.

de terceiro e quarto estágios, observouse que uma única aplicação de $23 \mathrm{~mm}$ de lâmina de água nas plantas de repolho, via sistema de irrigação por aspersão convencional, não removeu satisfatoriamente larvas da traça (Tabela 1). A baixa remoção de larvas foi decorrente, provavelmente, do estágio avançado em que as larvas se encontravam, resultando em uma menor suscetibilidade à remoção, aliada a um empupamento ocorrido, em larvas de quarto estágio, no período compreendido entre a colocação das larvas nas plantas de repolho e a irrigação destas (Tabela 2).

No segundo ensaio do primeiro experimento, realizado com larvas de primeiro e segundo estágios, verificou-se que a precipitação de $23 \mathrm{~mm}$, aplicada via sistema de irrigação por aspersão convencional, removeu satisfatoriamente larvas da traça (Tabela 3). A maior remoção de larvas neste ensaio foi ocasionada, provavelmente, pela maior suscetibilidade das larvas à remoção em decorrência de seu pequeno tamanho, quando comparado às larvas usadas no primeiro ensaio. Estes resultados estão de acordo com Harcourt, citado por McHugh \& Foster (1995), que verificou que larvas de primeiros estágios ao serem lavadas pela irrigação são incapazes de retornar à sua posição na planta e são afogadas nas poças de água formadas no solo ou nas axilas das folhas.

A precipitação tem influência no controle da traça-das-crucíferas pela remoção de larvas da planta, independente da idade da planta ou larva. Porém, foi observado que a remoção de larvas foi superior quando as plantas estavam com aproximadamente 40 dias de idade (folhas abertas) e quando larvas de primeiro e segundo estágios foram utilizadas.

No segundo experimento, nas parcelas onde o inseticida foi aplicado quando atingido o nível de dano, obser- 
Tabela 3. Porcentagem de remoção de larvas* de primeiro e segundo estágio de Plutella xylostella em plantas de repolho, por meio de irrigação por aspersão. Brasília, Embrapa Hortaliças, 1996.

\begin{tabular}{|c|c|c|c|}
\hline Idade da Planta & Testemunha & Irrigadas (23mm) & Média \\
\hline 50 dias & $10,00 * \star$ & 52,00 & $31,00 \mathrm{a}$ \\
\hline 70 dias & 7,00 & 29,00 & $18,00 \mathrm{~b}$ \\
\hline Média & $8,50 \mathrm{~A}$ & $40,50 B$ & \\
\hline
\end{tabular}

* Porcentagem de remoção de larvas, incluídas perdas no transporte.

** média de 10 plantas. Coeficiente de variação $=23,80 \%$

Médias seguidas pela mesma letra (maiúscula ou minúscula) não diferem estatisticamente entre si, pelo teste de Tukey, a $5 \%$ de probabilidade.

Tabela 4 Notas atribuídas às plantas de repolho nos três diferentes tratamentos. Brasília, UnB, 1997.

\begin{tabular}{cccc}
\hline Tratamento & Testemunha & $\begin{array}{c}\text { Aplicação } \\
\text { Semanal do } \\
\text { Inseticida }\end{array}$ & $\begin{array}{c}\text { Inseticida } \\
\text { Aplicado com } \\
\text { Nível de Dano }\end{array}$ \\
\hline Nota* $^{*}$ & $2,10^{\star \star} \mathrm{a}$ & $1,61 \mathrm{~b}$ & $1,74 \mathrm{ab}$ \\
\hline
\end{tabular}

* Notas atribuídas de acordo com o nível de dano: 1 = folhas sem dano; 2 = folhas com pouco dano; 3 = folhas com dano; e 4 = folhas com muito dano.

** Média de oito plantas. Coeficiente de variação $=34,52 \%$

Médias seguidas pela mesma letra não diferem estatisticamente entre si, pelo teste de Tukey, a $5 \%$ de probabilidade.

vou-se redução de $70 \%$ no número de pulverizações comparada ao tratamento onde as parcelas foram pulverizadas semanalmente. As médias das notas atribuídas para os três tratamentos, em geral, foram baixas em virtude do baixo nível de dano observado (Tabela 4).

As observações feitas neste experimento estão de acordo com as apresentadas por McHugh e Foster (1995) e Junqueira et al. (1998) que ao compararem a irrigação aplicada à cultura do repolho via aspersão convencional com a irrigação por gotejamento, verificaram que a infestação da traça pode ser reduzida simplesmente pelo uso da irrigação por aspersão.

As médias dos pesos das cabeças de repolho observadas nos três tratamentos demonstram que houve uniformidade na adubação e irrigação do experimento. As cabeças de repolho em todos os tratamentos, devido ao espaçamento utilizado, apresentaram-se com tamanho médio, compactas e densas, conforme preferência imposta pelo mercado consumidor. Não houve diferença estatística significativa entre as médias dos três tratamentos, sendo que o peso das cabeças de repolho variou de $1.322 \mathrm{~g}$ a $1.606 \mathrm{~g} / \mathrm{cada}$.
As pulverizações com o inseticida no campo deverão ser iniciadas quando os danos da traça observados aleatoriamente na cultura atingirem o nível de dano econômico pré-estabelecido. Este método é simples de ser realizado, requer em média, um minuto por planta para ser executado e não exige o manuseio das folhas e plantas. Ainda, sua utilização não reduz a produção comercial da lavoura (Castelo Branco et al., 1996).

Verificou-se que, se o produtor obedecer à demanda de água exigida pela cultura do repolho, somente com a irrigação poderá obter o controle efetivo da traça-das-crucíferas.

A irrigação aplicada à cultura via aspersão convencional pode vir a ser utilizada como parte de programas de manejo integrado da traça-das-crucíferas, reduzindo a quantidade de inseticidas empregada no ciclo da cultura e permitindo aos produtores enviar produtos mais saudáveis ao mercado consumidor.

\section{AGRADECIMENTOS}

Os autores agradecem ao PIBIC $\mathrm{UnB} / \mathrm{CNPq}$ pela concessão de bolsa, à Embrapa Hortaliças e à Fazenda Água Limpa - Universidade de Brasília, pelo apoio logístico, ao professor José
Ricardo Peixoto (UnB, FAV), por sua colaboração na atribuição de notas no segundo experimento e a Sieglinde Brune (Embrapa Hortaliças), pela cuidadosa revisão do manuscrito.

\section{LITERATURA CITADA}

CARBALLO, M.V.; HERNÁNDEZ, M.; RUTILIO, J.Q. Efecto de los insecticidas y de las malezas sobre Plutella xylostella (L) y su parasitoide Diadegma insulare (Cress) en el cultivo de repollo. Manejo Integrado de Plagas, v. 11, p. 1-20. 1989.

CASTELO BRANCO, M.; MELO, P.E. Avaliação de inseticidas e bioinseticidas para o controle da traça-das-crucíferas no Distrito Federal. Horticultura Brasileira, Brasília, v. 10, n. 2, p. 116-117, 1992.

CASTELO BRANCO, M.; VILLAS BOAS, G.L.; FRANÇA, F.H. Nível de dano de traça-dascrucíferas em repolho. Horticultura Brasileira, Brasília, v. 14, n. 2, p. 154-157, 1996

CASTELO BRANCO, M. FRANÇA, H.F.; VILLAS BÔAS, G.L. Traça-das-cruciferas (Plutella xylostella) - Artrópodes de importância econômica, Embrapa Hortaliças, 1997, 4 p. (Comunicado Técnico 4).

COSTA, J.S.; JUNQUEIRA, A.M.R.; SILVA, W.L.C.; FRANÇA, F.H. Impacto da irrigação via pivô-central na dinâmica populacional da traça-do-tomateiro. Horticultura Brasileira, Brasília, v. 14, n. 1, p. 82, 1996.

EMATER-DF. Produção de repolho em 1994-95 no D. Federal e região do entorno. Informativo da Produção Agrícola - IPAGRICOLA, 1996.

FRANÇA, F.H.; CORDEIRO, C.M.T.; GIORDANO, L.; RESENDE, A.M. Controle de traça-das-crucíferas em repolho. Horticultura Brasileira, Brasília, v. 3, n. 2, p. 50-51, 1984.

GUIMARÃES, A.L.; VILLAS BÔAS, G.L. Flutuação populacional da traça (Plutella xylostella) em repolho e seu principal inimigo natural Apanteles sp. no Distrito Federal. Horticultura Brasileira, Brasília, v. 7, n. 1, p. 56, 1989.

JUNQUEIRA, A.M.R.; COSTA, J.S.; CASTELO BRANCO, M.; FRANÇA, F.H. Impacto de diferentes lâminas e sistemas de irrigação nos danos de Plutella xylostella em plantas de repolho. In: CONGRESSO BRASILEIRO DE OLERICULTURA, 38, 1998, Petrolina, Resumos... Petrolina: SOB, 1998.

McHUGH, J.J.Jr.; FOSTER, R.E. Reduction of Diamondback Moth (Lepidoptera: Plutellidae) Infestation in Head Cabbage by Overhead Irrigation. Journal of Economic Entomology, v. 88 , n. 1 , p. $162-168,1995$.

SHELTON, A.M.; ROBERTSON, J.L.; TANG, J.D.; PEREZ, C.; EIGENBRODE, S.D.; PREISLER, H.K.; WILSEY, W.T.; COOLEY, R.J. Resistance of diamondback moth (Lepidopetera: Plutellidae) to B. thuringiensis subspecies in the field. Journal of Economic Entomology. v. 86, n. 3, p. 697-705, 1994.

SNEDECOR, G.W.; COCHRAN, W.G. Statistical Methods. Ames, 1989. 503 p.

VILLAS BÔAS, G.L.; BRANCO, M.C.; GUIMARÃES, A.L Controle químico da traçadas-crucíferas em repolho no Distrito Federal. Horticultura Brasileira, Brasília, v. 8, n. 2, p. 10-11, 1990. 